\title{
On the Integration and Innovation of Huizhou Woodcarving in the Design of Modern Cultural and Creative Products
}

\author{
Wei Shu ${ }^{1 *}$, Fuliang Sun ${ }^{1}$ \\ ${ }^{1}$ Art School, HuangShan University, HuangShan, AnHui, 245041, China
}

\begin{abstract}
Through combining the cognition of the current development of the cultural and creative industry and field research in ancient villages in Huizhou, the author had the reflection of the integration and innovation of Huizhou woodcarving in the design of modern cultural and creative products. This paper first analyzes the cultural background of Huizhou woodcarving, and then studies the current situation of the design of cultural and creative products. Through exploring the artistic and cultural connotation of Huizhou woodcarving, innovative methods and ideas of the design of modern cultural and creative products are applied in the design of cultural and creative products of Huizhou woodcarving. This paper aims to promote the sustainable development and revitalization of Huizhou woodcarving in the contemporary era through innovative design practices.
\end{abstract}

\section{Introduction}

As one of the important carriers of Huizhou culture, Huizhou woodcarving has gone through a process of inheritance and development of thousands of years, thus becoming a very precious cultural heritage. With its rich themes of patterns, delicate and diverse decorative details and its strong national style and regional aesthetic characteristics, Huizhou woodcarving is with the high value of reference and application in the design of cultural and creative products. Through the integration of this traditional art and the design of modern products, it's integrated into modern cultural and creative products, thus enabling the people to have a deep understanding of Huizhou culture, so as to inherit this ancient skill, improve economic benefit and promote the sustainable development of traditional arts in contemporary society.

\section{Huizhou Culture and Huizhou Woodcarving}

\subsection{Huizhou Culture}

Huizhou is a historical concept of a region in the south of Anhui, which governed "one prefecture and six counties". Since its establishment in Qin Dynasty as a county, it has a history of more than two thousand and two hundred years, which is rarely seen in Chinese history. The unique natural environment of Huizhou enabled it to develop its unique Shanyue culture. The later immigration from the Central Plain promoted the integration of Shanyue culture and Central Plain culture[1]. The relatively stable regional pattern of
Huizhou enabled the integrated culture to develop steadily and accumulate continuously, thus forming a distinctive Huizhou cultural circle, in which different forms of Huizhou culture were cultivated, such as Xin'an Neo-Confucianism, Xin'an Painting School, Huizhou block print, Huizhou seal cutting, Huizhou architecture and Huizhou Opera. Huizhou culture flourished in the Ming and Qing dynasties and spread widely along the well-connected waterways, and became famous at home and abroad for its numerous merchants and prosperous literary style. In a word, Huizhou culture is an outstanding representative and miniature of traditional Chinese culture.

\subsection{Xin'an Neo-Confucianism and Huizhou Woodcarving}

"Xin'an Neo-Confucianism" is the most concentrated embodiment of the thoughts and academic culture of ancient Huizhou. Zhu $\mathrm{Xi}$, the accomplished scholar of Neo-Confucianism, put forward a series of important thoughts, including "heavenly principles", "human desires", "moral principles and profits", "studying the nature of things" and "the unity of knowing and doing"[2]. "Xin'an Neo-Confucianism" is the ideological foundation of Huizhou culture, its prosperity and development had greatly promoted the development of other cultural forms and had far-reaching influence on the emergence and development of the art of Huizhou woodcarving, especially on the ideological contents and cultural implications of Huizhou woodcarving.

\footnotetext{
"Corresponding author's e-mail: shuwei@hsu.edu.cn
} 


\subsection{Huizhou Merchants and Huizhou Woodcarving}

With its practical and rational spirit of combining Confucianism and business, Xin'an Neo-Confucianism had promoted the rise and development of Huizhou merchants. The geographical relationship and consanguinity of Huizhou were united in the same patriarchal clans, making the Huizhou merchants have a strong concept of clans and consciousness of hometown. Huizhou merchants who "left the land but always stayed connected to the hometown" attached great importance to constructing ancestral halls and mansions to "honor the ancestors, flaunt filial piety and show off their wealth"[3]. Thus, Huizhou woodcarving was widely used in Huizhou architecture and could be seen both in urban and rural areas, which had particularly direct and great influence on Huizhou woodcarving(Figure 1).

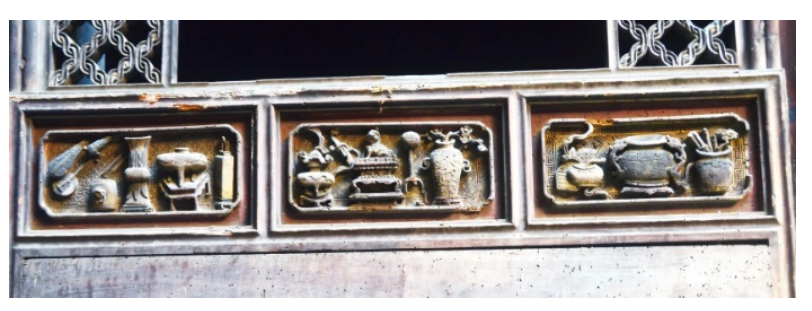

Figure 1. Building components of the former residence of a Huizhou merchant

\subsection{Xin'an Painting School and Huizhou Woodcarving}

"Xin'an Painting School" is the representative of painting in Huizhou with the common features of "advocating Ni Huang and delineating natural views"[4]. They advocated the philosophy of abandoning to and being inspired by nature. Their works presented unique artistic style and aesthetic feeling with unworldly appeal, which influenced not only the development of landscape painting but also the development of other forms of culture and art, woodcarving included. The influence of Xin'an Painting School on Huizhou woodcarving is mainly reflected in three aspects: first, its artistic thought of learning from nature influenced the creation of Huizhou woodcarving, making the natural scenery of Huizhou directly become the theme of Huizhou woodcarving; second, in terms of composition and layout, Huizhou woodcarving absorbed the simple and plain expression techniques of Xin'an Painting School, thus having a simple, expressive and refreshing style close to Xin'an Painting School; third, some painters of the Xin'an Painting School were also engaged in woodcarving, which had undoubtedly improved the artistic level of woodcarving.

\subsection{Huizhou Block Print and Huizhou Woodcarving}

Huizhou block print is the artistic crystallization of the cooperation between painters, carve workers and printers from Huizhou, and plays an important role in the history of Chinese culture and art. Huizhou woodcarving is very similar to Huizhou block print in art and techniques due to their same origin. Huizhou block print mostly creates shapes with line drawing technique, abandons large contrasts of black and white, but express the shapes and composition relationships with lines, thus having a delicate, fine, elegant and solemn artistic style[5]. It's with a rich lyrical flavor and scholar style. All these artistic methods and carving techniques, especially the method of creating shapes with lines, has directly influenced the creation of Huizhou woodcarving. In addition, some printmaking artists were also engaged in the creation of woodcarving, which greatly promoted the development of Huizhou woodcarving.

\subsection{The History of Huizhou Woodcarving}

As a national intangible cultural heritage, Huizhou woodcarving has the largest number of works, widest themes and most ingenious techniques among the numerous kinds of carvings in Huizhou. Huizhou is a place abundant in wood, providing a solid foundation for the woodcarving artists to bring their wisdom into play, and woodcarving is widely used in the decoration of buildings, furniture and daily articles. In the early years of Ming Dynasty, Huizhou woodcarving already began to take shape, with a simple and unadorned style and mainly adopting the technique of flat relief. After the middle of Ming Dynasty, with the increase of Huizhou merchants' wealth, they had stronger awareness of showing off in the hometown, the style of woodcarving was gradually transformed to the style of delicate and detailed expression, and flat relief was replaced by multilayer carving[6].

\section{The Decorative Characteristics and Artistic Value of the Pattern of Huizhou Woodcarving}

In terms of creation techniques, color combination and the application of decorative patterns, the patterns of Huizhou woodcarving have strong national epochal characteristics and are with unique artistic styles and expression techniques, thus having excellent value of research and reference for artistic forms of later generations[7].

\subsection{The Contents of Huizhou Woodcarving}

The patterns of Huizhou woodcarving are with very diverse themes, from natural scenery to lucky patterns, from myths to scenes of everyday life, among which the most characteristic part is the stories and legends of characters[8]. The characters are created vividly with delicate and detailed expression, representing the social activities in a lifelike manner and containing their universal ideals and expectations for the future, thus are the miniature of the thoughts, cultures and cultural styles of Huizhou in specific historical periods. 


\subsection{The Artistic Style of Huizhou Woodcarving}

In terms of style, the patterns of Huizhou woodcarving are grand and magnificent yet delicate and ingenious. They are with complete features and outstanding and unified themes. They are in good order and with clear purposes, the contents of the stories are positive and simple, which are expressed through ingenious carving techniques and rich gradation, and the diverse themes enable them to suit both refined and popular tastes.

\subsection{The Cultural Value of Huizhou Woodcarving}

Through the carving of decorative patterns, Huizhou woodcarving transmits strong concepts of regional culture and national spirits. In addition to their strong aesthetic value, the patterns of Huizhou woodcarving are with very high practical value and typical educating effects, thus are a perfect combination of decorative art and practical art[9]. Not only do the patterns of Huizhou woodcarving transmit the pursuit of ancient Huizhou people for beautiful things, they also transmit the profound connotation and cultural deposit of the history and culture of Huizhou.

\section{The Current Situation of the Integration of Huizhou Woodcarving and Cultural and Creative Products}

Nowadays, more and more people regard the development of cultural and creative industry as an important indicator of the comprehensive strength of a country. The cultural exportation between countries is becoming increasingly frequent, cultural and creative industry plays an indispensable role in the current cultural economic market and has become an important part of the cultural consumption system.

\subsection{The Cultural and Creative Industry}

The cultural and creative industry is an emerging industry with creativity as the core, which was generated in the context of globalization. It emphasizes the development and marketing of intellectual property rights of a main culture or cultural element by individuals (teams) through technologies, creativity and industrialization. Creative concepts play the leading role in it and a complete industry is formed for culture and knowledge. It's an industry with the resource of culture, the means of creativity and the purpose of industry, which is systematic, popular and easy to spread. In different regions, organizations and fields, different things are emphasized in the cultural and creative industry.

\subsection{The Design of Cultural and Creative Products}

In the discussion of cultural and creative products, this paper emphasizes the integration of culture and creativity and the integration of culture and product design with the creativity and wisdom of designers, during which the key is the recreation of cultural value through cultural and creative products and the core is the culture underlying the appearance of products. The design of cultural and creative products is the integration of the added value other than the practical functions of things such as culture, history, traditional arts and aesthetic experience with the useful articles through creative design. Through various methods of creative design, culture is integrated into life in a skillful way, which reflects the essence of traditional culture and improves the quality of life and aesthetic tastes of the people.

\subsection{The Current Situation of Relevant Cultural and Creative Industry of Huizhou Woodcarving}

On the whole, the cultural and creative industry of Huizhou has such problems as few categories of products, outdated ideas of design, weak expression of regional culture and lack of practicability[10]. The market of cultural and creative products in Huizhou is in an urgent need of deep development, and cultural and creative products integrating Huizhou culture are with great space of design and potential of development. As one of the most characteristic representatives of Huizhou culture, Huizhou woodcarving promises broad market prospect when integrated with the design of modern cultural and creative products.

\subsubsection{A Review of the Cultural and Creative Products in Huizhou.}

Through the field research of cultural and creative products in the core region of Huizhou culture in the south of Anhui, it's discovered that although this region has advantaged cultural resources, the existing cultural and creative products related to Huizhou culture are mostly in the form of traditional artware, these characteristic cultures haven't been integrated with the design of modern products; part of the cultural and creative products have the characteristics of modern products, but the cultural symbols are expressed in a shallow way instead of being expressed deeply in the core connotation; there are a few cultural and creative products that are quite successful, thus having some referential value.

\subsubsection{The Current Situation of the Cultural and Creative Products of Huizhou Woodcarving.}

With its delicate and ingenious carving techniques and unique aesthetic implications, Huizhou woodcarving has always occupied an important position in the market of ancient village souvenirs. However, surveys have shown that most of the souvenirs in Huizhou related to Huizhou woodcarving are simple duplication of woodcarving elements without the integration of modern thoughts of design(Figure 2), they can even barely be regarded as real cultural and creative products. 


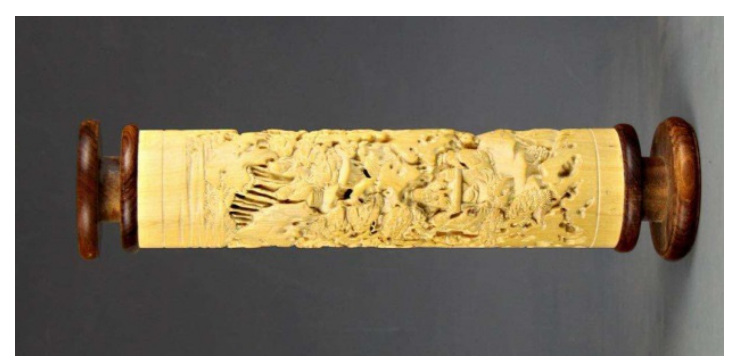

Figure 2. Joss stick support made of boxwood in Huizhou

\subsubsection{Problems and Needs of the Cultural and Creative Products of Huizhou Woodcarving.}

Through summarizing the materials obtained in the investigation, we found that the products related to woodcarving in the cultural and creative market of Huizhou basically fall into three categories: printed products represented by postcards and envelopes, which directly use the patterns of woodcarving; carved brush pot made of bamboo or wood, which simply copy the patterns; and food represented by common cakes and pastries on which patterns are branded.

In the contemporary age when people have increasing spiritual needs, consumers are no longer satisfied with cultural and creative products with shallow expression of culture, but have begun to pursue products with deep cultural implications and strong cultural appeal[11]. And the corresponding needs of the market are reflected in the following aspects: a overwhelming majority of the tourists intend to buy products with local characteristics and practical value as souvenir or gifts for friends and relatives. Compared to existing products, they prefer to buy modern products redesigned with a combination of cultural connotations.

\section{The Application of Huizhou Woodcarving in the Design of Cultural and Creative Products}

\subsection{Referential Experience and Examples}

Cultural and creative industry originated from abroad, and the most popular example in the early years was the series of cultural and creative products launched by the Metropolitan Museum of Art based on the cultural relics in the museum. In recent years, excellent cultural and creative products in China have sprung up like mushrooms, such as the U-shaped pillow by the Palace Museum combined with patterns of Diverse Sea Creatures, the multi-functional turtle-shaped earphone winder by Shanghai Museum and the creative seal cup by Suzhou Museum combined with the $\mathrm{Ru}$ porcelain Hengshan Cup of Wen Zhengming(Figure 3). These widely praised cultural and creative products all integrated rich cultural implications in the products through in-depth research of traditional culture, they suit the psychological needs of contemporary consumers with unique cultural flavor and aesthetic feelings and are at the same time with high practical values.

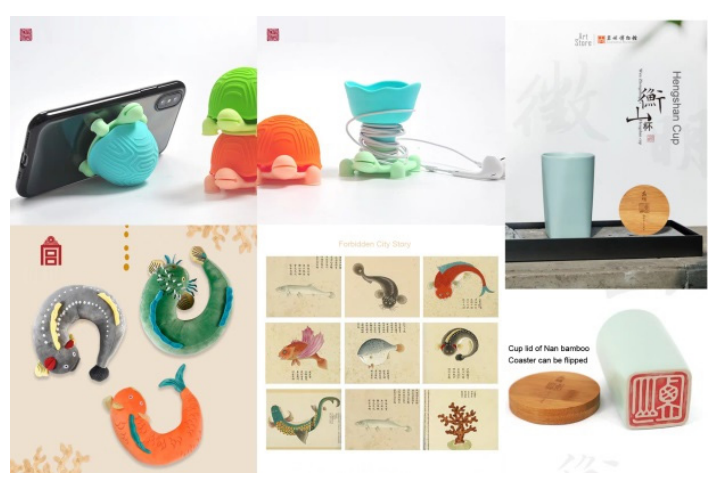

Figure 3. Excellent domestic cultural and creative products

\subsection{The Core of the Design of Cultural and Creative Products of Huizhou Woodcarving}

Through our analysis of excellent examples, we hold that the core of the design of cultural and creative products of Huizhou woodcarving is to combine innovation, practicability and interest on the basis of meeting the need of cultural inheritance through the intervention of modern aesthetic philosophy. Culture acts as the core of the cultural and creative products of Huizhou woodcarving, and culture and products are integrated through design thinking with the practical products as the medium, thus designing outstanding cultural and creative products with practical value, aesthetic value, innovative value and the value of cultural inheritance and realizing the spreading of Huizhou culture among the people[12].

\subsection{The Design Orientation of Cultural and Creative Products of Huizhou Woodcarving}

Through the investigation, research and analysis we conducted, we found that the young generation is the main consumer group of modern cultural and creative products. Their consumption capacity is mainly concentrated in stationery, daily utensils and clothes which integrate decorative and practical values; compared with high-end and cheap products, products at medium prices sell better; the sales of the products are no longer limited to traditional channels and online platforms have become the main channels. Therefore, we regard small and practical cultural and creative products with high cost performance, which suit the aesthetic orientation of young people, as the orientation of the design of cultural and creative products of Huizhou woodcarving.

\subsection{Approaches of Integrating Huizhou Woodcarving and Cultural and Creative Products}

According to the requirement of the design orientation, patterns of Huizhou woodcarving containing such themes as kindness, filial piety, loyalty, righteousness and academic pursuit for political careers are classified(Figure 4). In combination with such spiritual contents as the historical background, environments and states of mind of the works, the cultural connotations of 
the works are clarified, and the patterns and shapes are redesigned with the theoretical support of modern aesthetic philosophy, during which the colors, shapes and materials favored by young consumers are integrated, and while modernizing the aesthetic flavor, the spiritual values in them remain unchanged. Then, following the principle of pragmatism and in combination with techniques of Huizhou woodcarving, they are applied in the design of modern cultural and creative products through such approaches as collage, grafting and repeating.

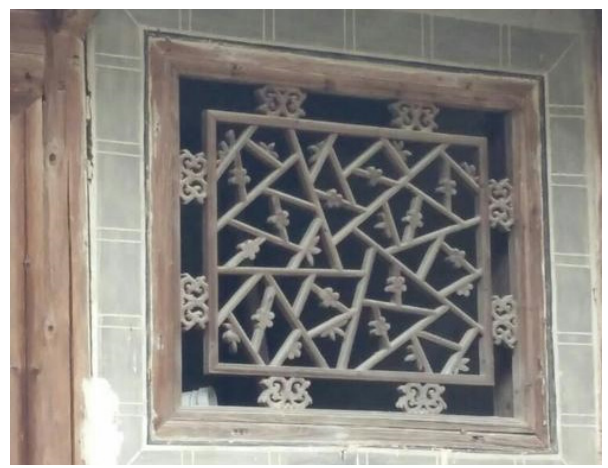

Figure 4. The "Cracking Ice" windowpane in Huizhou with the implied meaning of persevering in studies in spite of hardships

\subsection{Design Practices of the Integration of Huizhou Woodcarving with Cultural and Creative Products}

Through the above-mentioned approaches, we conducted a series of practices in such fields as stationery, daily utensils and clothes, which are easy for the people to accept and buy. A series of cultural and creative products for young consumers were designed on the basis of Huizhou woodcarving, aiming to spread Huizhou culture, inherit and innovate the art of Huizhou woodcarving.

\subsection{1 "Pretty Outside and Intelligent Inside" Pastry Mould (Figure 5).}

Inspired by the silk ball of the "Official Residence" in Xidi, this product implies the meaning of "whoever gets the colorful ball shall be lucky and everything shall go as they wish". In combination with the daily utensil of Huizhou woodcarving mould, the shape of Huizhou chrysanthemum was adopted to design the silk ball pastry mould. The name "pretty outside and intelligent inside" implies that the user is a pretty, intelligent and virtuous person.

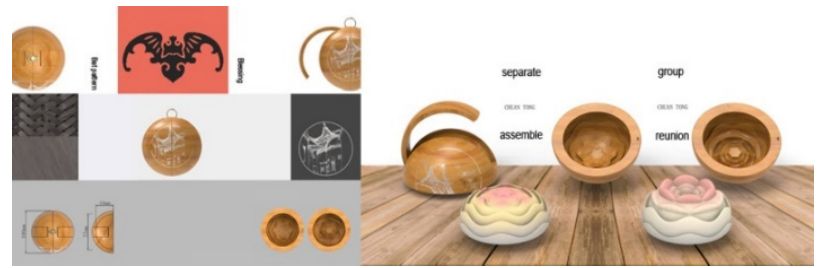

Figure 5. "Pretty Outside and Intelligent Inside" Pastry Mould

\subsection{2 "Huizhou Window Lattice" Hand-held Electric Fan (Figure 5).}

Inspired by the woodcarving window lattice in Huizhou architecture, and through extracting the window lattice pattern of ice plum of the "Official Residence" in Xidi, this product ingeniously combines the function of window lattice of ventilation, lighting, decoration and viewing with the electric fan. The ice plum has the traditional implication of the coming of happiness after suffering, reflecting how it can bring pleasure for the tourist in blistering summer days.

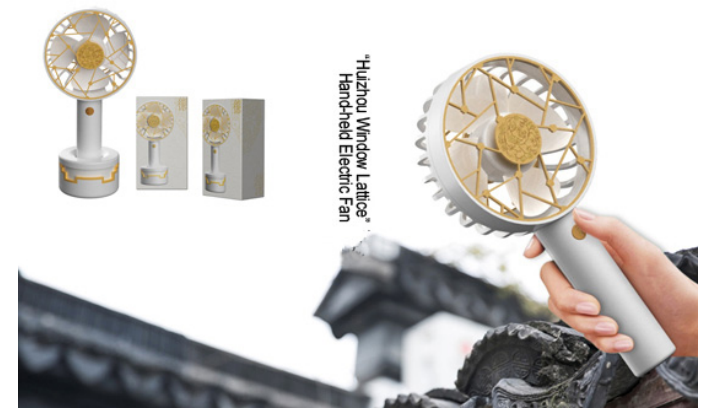

Figure 6. "Huizhou Window Lattice" Hand-held Electric Fan

\subsection{3 "Listening" Earphone (Figure 5).}

Compared to the last product, this product is inspired by the woodcarving window lattice culture of Huizhou Architecture and combines the landscape of Huizhou and the shapes and colors of the buildings, implying the meaning of coming to Huizhou and listening to its thousand-year stories. Wood is used in the parts of this product and its package, with delicate and fine details in some parts, reflecting the woodcarving techniques of Huizhou.

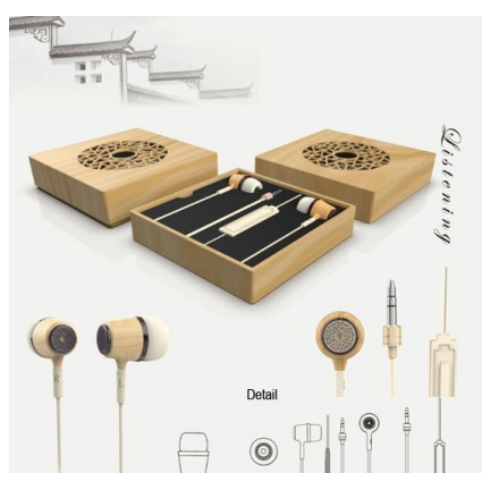

Figure 7. "Listening” Earphone

\section{Conclusion}

Huizhou is a place with abundant cultural resources and profound cultural deposit, and Huizhou woodcarving has a high reputation at home and abroad with its ingenious techniques and delicate aesthetic shapes. Extracting the essence of Huizhou woodcarving and applying them in the design of cultural and creative products can not only easily transmit the cultural connotation of Huizhou culture, but also greatly improve the aesthetic taste of the products. At the same time, these cultural and creative 
products of Huizhou woodcarving with exquisite design help spread Huizhou culture and the folk arts of Huizhou and enriches the cultural and tourist resources and tastes of Huizhou. The integration of modern theories and practices of design and Huizhou woodcarving surely will promote the revitalization of the techniques and culture of Huizhou woodcarving in the new era.

\section{Acknowledgment}

Research on the Development and Design of Huizhou Cultural Creative Tourism Commodities, Key Project of Humanities and Social Sciences $\mathrm{s}$ of Colleges and Universities in AnHui, Liang Jun, SN: SK2018A0392

\section{References}

1. Luo, Z. (2009) On the Cultural Implications and Cultural Characteristics of Huizhou Woodcarving. Xi'an Academy of Fine Arts, Xi'an.

2. Zhou, X.,(2005) Xin'an Neo-Confucianism·A Pandect of Huizhou Culture. Anhui People's Publishing House, Hefei.

3. Wang, T., Wang, S. (2005) Huizhou Merchants·A Pandect of Huizhou Culture. Anhui People's Publishing House, Hefei.

4. Guo, Y., Yu, H., Hu, C. (2005) Xin'an Painting School-A Pandect of Huizhou Culture. Anhui People's Publishing House, Hefei.

5. Zhang, G. (2005) Huizhou Block Print·A Pandect of Huizhou Culture. Anhui People's Publishing House, Hefei.

6. Bao, Y. (2005) Huizhou Crafts·A Pandect of Huizhou Culture. Anhui People's Publishing House, Hefei.

7. Wu, H. (2017) On the Cultural Inheritance of Ancient Villages in Anhui and the Design of Modern Cultural and Creative Products. Anhui Engineering University, Wuhu.

8. Zhu, M. (2010) On the Inheritance and Innovation of Huizhou Woodcarving Art. Anhui Engineering University, Wuhu.

9. Liu, M. (2017) On the Integration and Innovation of Traditional Carving Art and Modern Fashions-with Huizhou Carving as an Example. Jiangxi Social Sciences, 3:245-251.

10. Huang, Z. (2018) On the Application of Woodcarving in Huizhou Architecture in Modern Fashion Design. Masterpieces of Nature, 1:49.

11. Yang, C. (2015) On the Design and Presentation of Woodcarving in Ancient Buildings of Huizhou. Hundred Schools in Arts, 4:245-246.

12. Shu, W., Sun, F. (2014) Analysis and Reflection on the Current Situation of the Design of Souvenirs. Journal of Huangshan University, $1: 20-23$. 